\title{
German banks' behavior in the low interest rate environment
}

\author{
Ramona Busch ${ }^{1} \cdot$ Helge C. N. Littke ${ }^{1}$. Christoph Memmel ${ }^{1}$ (1) \\ Simon Niederauer ${ }^{1}$
}

Accepted: 28 October 2021 / Published online: 21 December 2021

(C) The Author(s) 2021

\begin{abstract}
Using data from a quantitative survey of German banks at three points in time (2015, 2017 and 2019), we analyze the impact of changes in the interest rate level on banks' net interest income and the countermeasures they take. A decline in the interest rate level has a more negative impact on net interest income, the longer the decline lasts and the lower the interest rate level is. This impact softens with increasing risk of changes in the present value of banking books. We do not find that banks generally increase their risks following a drop in income. However, poorly capitalized banks subsequently increase the credit risk of their bond portfolio. After a fall in operational income, banks increase their fee and commission income and reduce their costs. In addition, banks tend to extend their mortgage lending after a drop in their interest income.
\end{abstract}

Keywords Banks' net interest margin - Fee and commission income - Low interest rate environment $\cdot$ Risk-taking $\cdot$ Administrative costs

JEL classification G 21

$凶$ Christoph Memmel

christoph.memmel@bundesbank.de

Ramona Busch

ramona.busch@bundesbank.de

Helge C. N. Littke

helge.littke@bundesbank.de

Simon Niederauer

simon.niederauer@bundesbank.de

1 Deutsche Bundesbank, Wilhelm-Epstein-Straße 14, 60431 Frankfurt, Germany 


\section{Introduction}

Low interest rates negatively impact banks' interest income. This is what most empirical studies detect, i.e., they find a positive relationship between banks' net interest margins and the interest rate level in the long term (see, for instance, Albertazzi and Gambacorta (2009)). ${ }^{1}$ Some studies additionally claim that the time since the drop in the interest rate level is important and that the relationship intensifies in a low interest rate environment (see, for instance, Claessens et al. (2018) and Klein (2020)). We use three waves of a quantitative survey among small- and medium-sized German banks to answer several questions concerning banks' behavior in a low interest environment. That means that we use banks' forecasting data and not actual financial statements. However, the advantage is that we have bank results for different scenarios of the term structure, which allows us to isolate the effect of interest rate shocks. Figure 1 shows the deviation of banks' net interest income as a consequence of a negative shift in the interest rate level, for three waves of a quantitative survey, which confirms these claims. ${ }^{2}$ In our empirical study, we find that the deviation of a bank's net interest margin amounts to $5 \mathrm{bp}$ per year since the shock and per $100 \mathrm{bp}$ shift in the interest rate level and that the interest rate level at the time of the shock is relevant: the lower the initial interest rate level, the stronger the negative effect on the net interest margin.

The effect of a change in the interest rate level depends not only on macro-economic variables, but also on bank-specific ones. Kerbl and Sigmund (2016) argue that, under negative interest rates, net interest margins decline more due to a decrease in interest rates if deposits are floored at zero. They find that small regional banks are hit hardest, because they have a large share of deposits. Heider et al. (2017) also highlight the impact of negative interest rates on banks with a large share of deposits. They show that the introduction of negative interest rates by the European Central Bank (ECB) led to increased risk-taking on the part of euro area banks that have a large share of deposits. To account for the important role of deposits, we look at a bank's long-run pass-through, which reflects the business model and, indirectly, the extent of their deposit funding: A bank that relies on customer deposits for funding and grants loans is likely to have a large mismatch in its long-run pass-through: On the asset side, changes in the interest rate level will sooner or later lead to corresponding changes in the loan rates, whereas deposit rates do not change as much, even in the long run. As in Dräger et al. (2021), we find that changes in the interest rate level have a strong impact on banks with a large pass-through mismatch and that the exposure to interest rate risk softens the effect. Both effects are substantially more pronounced if there is an increase in the interest rate level than if there is a decrease.

Since net interest income is by far the most important income source for banks, a change in the net interest income can significantly affect a bank's business. Several

\footnotetext{
1 Alessandri and Nelson (2015) and Busch and Memmel (2017) find that, in short run, the opposite effect occurs, i.e., that the banks' net interest margin goes down when the interest rate level rises. In the long run, they find the effect documented in the literature.

2 When we talk about a shift in the interest rate level, we assume a parallel shift in the entire term structure of the German risk-free interest rate, which takes place at the beginning of the survey's five-year forecast horizon, i.e., the year-end term structure of the risk-free interest rate undergoes a parallel shift of $-100 \mathrm{bp}$ (in the case of a decrease) or $+200 \mathrm{bp}$ (in the case of an increase).
} 
5

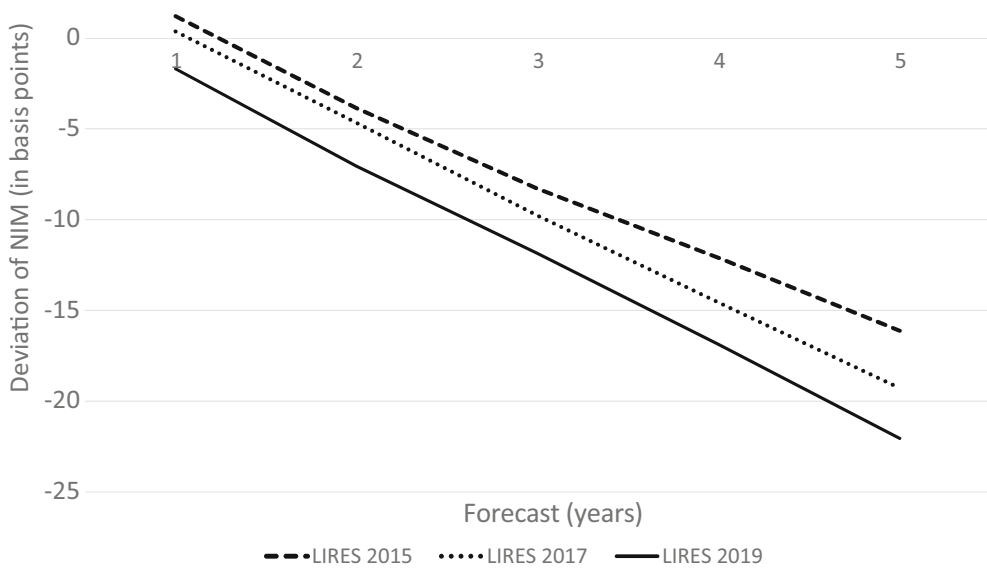

Fig. 1 Deviation of the Banks' NIM after a Downward Interest Rate Shock. This figure shows the deviation of banks' net interest margin (NIM, i.e., the deviation from their NIM under the scenario of a time-constant term structure) as a consequence of an ad hoc decrease in the interest rate level ( $-100 \mathrm{bp})$ over the respective five-year forecast horizon for each of the three waves of the Low Interest Rate Environment Survey (LIRES 2015, LIRES 2017, LIRES 2019). The samples include almost all German small- and medium-sized banks. The baseline for each year is the NIM under the assumption of a constant interest rate level

empirical studies find a negative correlation between interest rates and banks' risktaking (see, for example, Delis and Kouretas (2011); Maddaloni and Peydró (2011); Altunbas et al. (2014); Basten and Mariathasan (2018)). However, Boungou (2020) finds the opposite effect. Maddaloni and Peydró (2011) find that low short-term interest rates soften lending standards in the euro area and USA. Furthermore, if interest rates stay at a low level for an extended period, the softening of the lending standards is amplified. These studies seem to contradict studies like Brei et al. (2019) and Bikker and Vervliet (2017), who find that interest rates are positively correlated with loan loss provisions and risk weights. This finding is not necessarily inconsistent with the studies previously mentioned, however. Lower interest rates normally reduce credit defaults and improve the value of collaterals. Therefore, the credit quality of the existing credit portfolio should tend to improve. If the flow of new credits is significantly smaller than the stock of existing loans, a possible higher risk-taking in new loans would not be reflected immediately in credit provisions and risk weights. Concerning interest rate risk, Chaudron (2018) finds no evidence of Dutch banks increasing their risk in the low interest rate environment; their exposure to interest rate risk seems more related to the steepness of the term structure. In our study, we find no general relationship between a drop in a bank's income and its risk-taking. As a side effect, we document a change in the risk composition for banks with elevated exposure to interest rate risk: They reduce this risk and increase the underlying credit risk of their bond holdings.

Memmel et al. (2018) analyze changes in a bank's attitude toward risk, namely the change from risk-averse behavior to risk-seeking behavior. They investigate whether banks with declining operating profits seek to take on risk even if the remuneration 
for bearing such risk falls, which is a sign of risk-seeking behavior and can be seen as a form of risk-taking in the context of low interest rates. In their study of German banks, which includes the beginning of the period of low interest rates, they find that such behavior is not widespread, but seems to be relevant for individual banks. In our sample, we find that individual banks, specifically those whose equity ratio is very low, increase their risk-taking after a drop in their operational income by lowering the creditworthiness of their bond portfolio.

While the positive correlation between interest rates and the banks' net interest margin is well documented in the literature, the relationship between interest rates and overall profitability is less clear. This is because banks can partly offset the negative effects on net interest margins by expanding other income sources when interest rates decline (see, for instance, Basten and Mariathasan (2018) regarding Swiss banks). Lopez et al. (2020) show for a panel of 5200 banks from 27 countries that losses in interest income due to negative interest rates are offset by lower deposit expenses and gains in non-interest income. These gains from non-interest income stem less from fee-generating activities and more from capital gains. The authors emphasize that such capital gains are expected to offset the negative impact on the net interest margin only temporarily, as, for example, capital gains from securities can only be enjoyed once. In our empirical study, we use the operational income before valuation to capture the structural earning capacity of a bank. We find that banks only partly offset a drop in net interest income by expanding fee and commission income and by reducing administrative costs. The mitigating effect is estimated as 12 cent per euro of a decline in the net interest income.

Furthermore, some studies analyze the impact of interest rates on lending volume. Klein (2020) shows that lower net interest margins cause a lower loan growth. The reason for this could be that incentives to generate loans are stronger when potential earnings are higher. Under negative interest rates, however, this effect seems to vanish. By contrast, Molyneux et al. (2020) find weaker loan growth for countries with negative interest rates. In our study, we find that the volume of mortgage loans increases and the volume of consumer loans decreases for banks that are especially affected by a reduction in their net interest margin.

The 2015 and 2017 waves of the survey have already been analyzed in Busch et al. (2017) and in Dräger et al. (2021), but with a different focus. Busch et al. (2017) analyze the assumption of a static balance sheet. Dräger et al. (2021) investigate how banks deal with the risks associated with credit and interest business. In contrast to Dräger et al. (2021), we not only analyze the upward scenario of the 2017 wave of the survey, but also the waves of 2015 and 2019, i.e., for each bank we have a time-series from 2014 to 2023 (see Table 1). Moreover, we especially scrutinize banks' actions to mitigate the effects of the low interest rate environment.

The paper is structured as follows: The data we use are explained in Sect. 2. In Sect. 3 , we look at how an assumed interest rate shock impacts the net interest margin, and in Sect. 4, we analyze countermeasures against falling margins. Section 5 concludes. 
Table 1 Overview of the data structure

\begin{tabular}{|c|c|c|c|}
\hline Year / Wave & 2015 & 2017 & 2019 \\
\hline 2014 & $\begin{array}{l}\text { Financial } \\
\text { statement }\end{array}$ & & \\
\hline 2015 & \multirow{5}{*}{ Projections } & & \\
\hline 2016 & & $\begin{array}{l}\text { Financial } \\
\text { statement }\end{array}$ & \\
\hline 2017 & & \multirow{5}{*}{ Projections } & \\
\hline 2018 & & & $\begin{array}{l}\text { Financial } \\
\text { statement }\end{array}$ \\
\hline 2019 & & & \multirow{5}{*}{ Projections } \\
\hline 2020 & & & \\
\hline 2021 & & & \\
\hline 2022 & & & \\
\hline 2023 & & & \\
\hline
\end{tabular}

This table shows the time structure of the three waves of the Low Interest Rate Environment Survey (LIRES) in our study

\section{Survey}

\subsection{General aspects}

In this paper, we make use of three waves of a survey carried out by the Bundesbank and the Federal Financial Supervisory Authority ${ }^{3}$ among almost all small and mediumsized banks in Germany, namely in 2015, 2017 and 2019. These waves of the Low Interest Rate Environment Survey (LIRES), participation in which is mandatory, are carried out every other year and encompass a horizon of five years, for which the banks provide detailed projections of their financial statements as planned and under different scenarios. Additionally, banks also provide their financial statement of the preceding year. Hence, combining the three most recent waves (i.e., the 2015, 2017 and 2019 waves of the survey) allows us to analyze the low interest rate environment in Germany. In Table 1, we provide an overview of the structure of the survey data. For instance, for the 2015 wave of the survey, we have historical banking data from 2014 and projections for the subsequent five years for different interest rate scenarios.

Among the scenarios are a downward shift in the entire term structure of $100 \mathrm{bp}$ and an upward shift of $200 \mathrm{bp}$, where the shift takes place at the respective beginnings of the five-year periods, i.e., at 01/01/2015, 01/01/2017 and 01/01/2019. As the counterfactual, we choose the scenario of a constant term structure. When we look at macro- and bank-specific determinants of a bank's net interest income (Sect. 3), we use historical banking data and projections, yielding 15 years $=$ three times five years of forecasting (as in Fig. 1) and three times one year of historical data (2014, 2016 and 2018). In Sect. 4, we use historical banking data, more precisely changes in the data: We define as a change in income, the change in the net interest margin and the

\footnotetext{
3 Bundesanstalt für Finanzdienstleistungsaufsicht (BaFin).
} 
operation income margin (operational income before valuation divided by total assets) from 2014 to 2016. This change in income is used to explain the change in risk-taking or in financial statement values (such as fee and commission income, administrative costs or loan positions) from 2016 to 2018. By doing this we avoid time overlaps between the dependent and explanatory variables. In Table 2, we give an overview of the regressions used in this paper.

The data set is especially suitable for addressing issues of the impact of the interest rate level on a bank's net interest margin (NIM) because we not only have the banks' $N I M$ under the assumption of a downward shift and an upward shift in the interest rate level, but also the bank's NIM under the assumption of a constant interest rate level (which we use - as mentioned above — as our counterfactual). That enables us to isolate the effect resulting from a change in the interest rate level from other effects, for instance due to changes in the risk premiums or in the competitive situation. In addition, the projections under these three scenarios are subject to the assumption of a static balance sheet, i.e., maturing assets and liabilities are replaced by similar new instruments in terms of type, credit quality and original maturity at portfolio level, so that effects resulting from changes in the composition of the balance sheet or from changes in the amount of business are not present.

When we look at Table 3, where different interest rates at the respective cut-off dates for the three waves are shown, we see that the interest rates generally decrease from wave to wave; this is especially true of rates that banks set ("Loans to nonfinancial corporations" and "Sight deposits"). Looking at market rates ("Yields on debt securities outstanding" and "10y German government bond yield"), we notice that the rates in 2018 showed a slight increase.

Each wave contains almost all small- and medium-sized banks in Germany (2015: 1546 banks, 2017: 1535 banks, 2019: 1413 banks). The 2019 sample encompassed $89 \%$ of all German credit institutions and $38 \%$ of the aggregate balance sheet. Although the balance sheet coverage may appear, rather low-, small- and medium-sized banks in Germany (especially cooperative and savings banks) are the major source of funding for retail customers as well as small- and medium-sized businesses. At the end of 2018, the participants in the 2019 survey accounted for $77 \%$ of the entire retail credit volume. All banks participating in LIRES are under German supervision, whereas only those banks categorized as significant are subject to the direct supervision of the European Central Bank.

The sample composition varies between each wave of the survey, which is mostly because of banks formally exiting the sample due to mergers. ${ }^{4}$ However, if the overtaking bank remains in the sample, the overtaken bank essentially does as well. To account for this circumstance, synthetic banks are created by adding up the respective balance sheet positions of overtaking and overtaken bank(s) in all waves of the survey. For later analyses, the individual banks that were engaged in mergers will be replaced by these synthetic banks. This serves two purposes: Firstly, the analyzed sample is consistent in the sense that no overtaken bank is removed, although it indirectly remains in the sample after a merger. Secondly, the individual characteristics

\footnotetext{
4 While roughly 100 banks, respectively, exited the sample between each wave due to mergers, almost the same amount of new participants joined the sample between 2015 and 2017 . Hence, sample sizes in 2015 and 2017 are almost equal.
} 


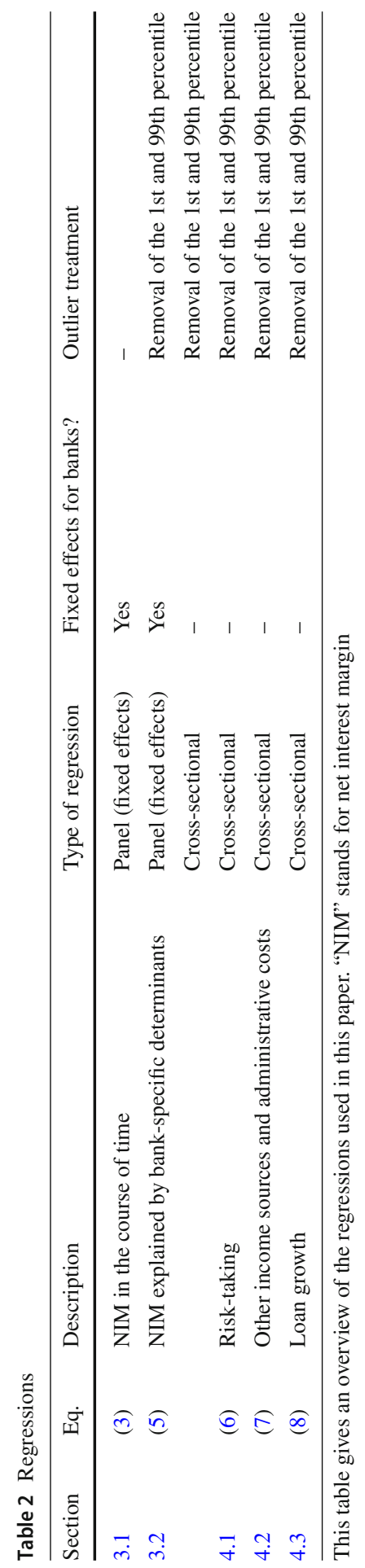


Table 3 Interest rate level at the caves' cut-off dates

\begin{tabular}{llll}
\hline Rates & 2014 & 2016 & 2018 \\
\hline Loans to non-financial corporations (new business) & $1.87 \%$ & $1.53 \%$ & $1.29 \%$ \\
Sight deposits (new business) & $0.22 \%$ & $0.07 \%$ & $0.02 \%$ \\
Banks' interest income (rel. to total assets) & $2.49 \%$ & $2.17 \%$ & $2.08 \%$ \\
Yields on debt securities outstanding issued by German residents & $0.6 \%$ & $0.2 \%$ & $0.3 \%$ \\
10y German government bond yield & $0.59 \%$ & $0.22 \%$ & $0.24 \%$ \\
10y German government bond yield, moving average & $3.12 \%$ & $2.49 \%$ & $1.84 \%$ \\
\hline
\end{tabular}

This table shows the interest rates at the cut-off dates $(31 / 12 / 2014,31 / 12 / 2016,31 / 12,2018)$ for the surveys of 2015, 2017 and 2019. Average values of the respective December except for "Banks' interest income (rel. to total assets)," which is the value for the whole year, and the 10y German government bond yields which are year-end values. The moving average (in row 6) has a window which is equal to the initial maturity of the bonds (i.e., 10 years). The moving average corresponds to the yield of a passive trading strategy where one invests in a revolving manner into par-yield bonds and takes out the interest payments (see Appendix 1)

of an overtaken bank are not attributed to more than one entity. Without the synthetic approach, an overtaken bank would appear twice in a regression, once as itself and once as part of the overtaken bank. Hence, this approach counteracts distortions of our results. Furthermore, all analyses in this paper are restricted to banks that participated in all samples.

\subsection{Summary statistics}

In Table 4, we show summary statistics of the net interest margin (NIM) for the three waves of the survey and the years of prognoses ("Years since the shift"). The numbers are given as the deviation from the NIM in the scenario of a constant term structure, i.e., the "deviation" (denoted by "C." to distinguish it from the differences in the time dimension often denoted by " D." or by “ D") does not signify a change in the time dimension, but the difference to the contemporaneous net interest margin under the scenario of a time-constant term structure. The column "Mean" of the "Scenario: -100 bp" is plotted in Fig. 1; the median, the 10th and the 90th percentile of the wave LIRES 2019 (upward scenario) are plotted in Fig. 2.

In Table 5, we show the summary statistics of bank variables that we use in Sect. 3.2 .

The variable Impact is the average deviation (over the five-year forecast horizon) of the NIM from the baseline of a constant term structure. This average deviation is negative for a drop in the interest rate level and positive for a rise in the interest rate level.

We define a bank's exposure to interest rate risk as a multiple of its duration. We measure it by the variable $I R R$, which gives the negative change in present value of a bank's banking book as a consequence of a 200 bp parallel upward shift in the entire 


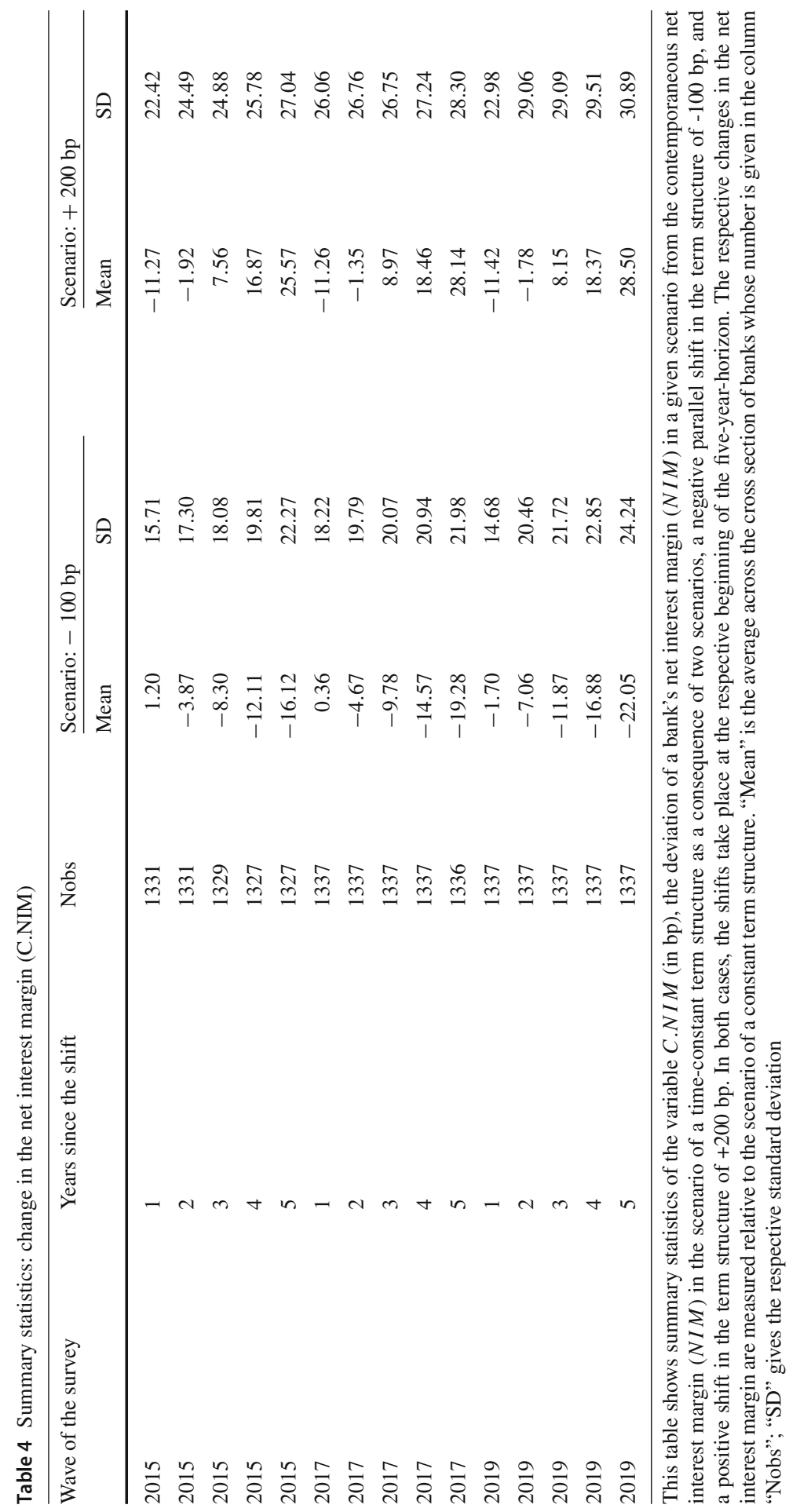


80

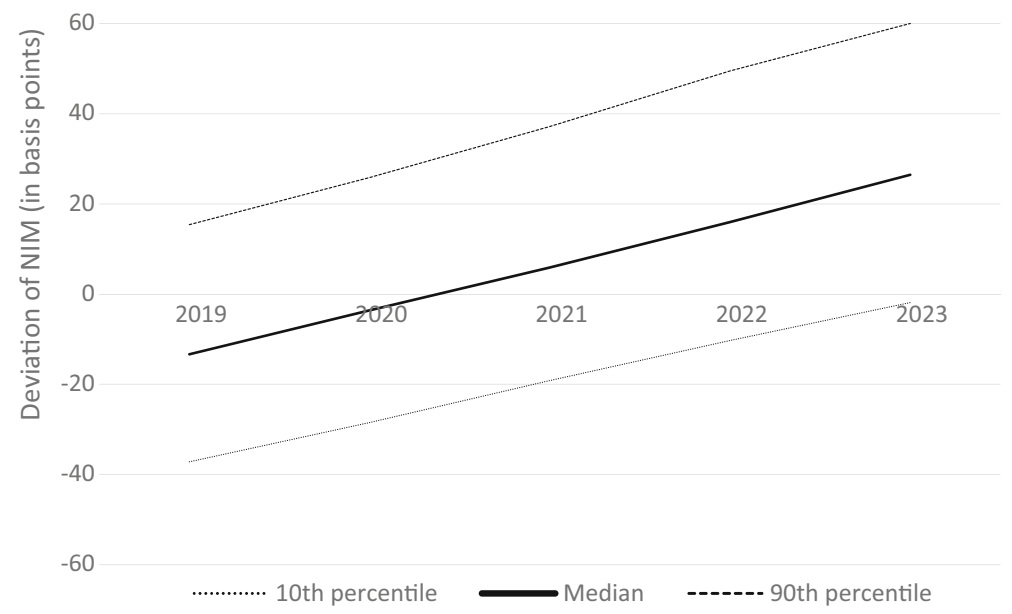

Fig. 2 Deviation of the Banks' NIM after an Upward Interest Rate Shock. This figure shows the deviation of banks' net interest margin (NIM, i.e., the deviation from their NIM under the scenario of a time-constant term structure) as a consequence of an ad hoc increase in the interest rate level (200 bp) at the beginning of 2019. The samples include almost all German small- and medium-sized banks. The baseline for each year is the NIM under the assumption of a constant interest rate level

term structure. ${ }^{5}$ The regulation stipulates that banks must report this figure in each quarter. It is normalized by a bank's total assets. For securities and other financial instruments with defined cash flows (for instance swaps), this change can be easily computed by the banks. For other financial products, especially for customer deposits, banks have to make additional assumptions (see Kerbl et al. (2019)).

To calculate the long-run pass-through $\theta_{i}$ for each bank $i$, a long-run pass-through $\theta^{j}$ is assigned to each balance sheet position $j .6$ For instance, for bond holdings it is set to one. By contrast, for positions that do not earn interest as equity or cash, it is set to zero. For balance positions whose payments depend on the interest rate level, but are not fully linked to it, such as sight deposits, we make use of the estimates in Memmel (2018).

$$
\theta_{i}=\sum_{j=1}^{J} w_{i, j} \cdot \theta^{j}
$$

where $w_{i, j}$ is the share of balance position $j$ in the balance sheet of bank $i$. According to the summary statistics in Table 5 , the average value is $25.32 \%$, meaning that an increase of $100 \mathrm{bp}$ in the interest rate level leads to an increase of $25.32 \mathrm{bp}$ in a bank's net interest margin $(N I M)$ in the long run. When we compare this figure with the

\footnotetext{
5 This so-called Basel interest rate shock has become standard practice in European banking supervision to measure interest rate risk in the banking book.

6 In total, there are 29 positions (17 asset positions and 12 liability positions). Note that positions on a bank's liability side are assigned a negative weight and that positions with an assumed pass-through of zero, like cash, are not included.
} 
values from the projections (after five years), we find in the downward scenario 16 to $22 \mathrm{bp}$ and in the upward scenario 14 to $15 \mathrm{bp} .^{7}$ The variable $C R$ gives a bank's capital ratio (CET1 divided by risk-weighted assets $(R W A)$ ), whose mean is around $16.5 \%$. The dummy variable Swap has a mean of 0.47 , meaning that in $47 \%$ of observations, banks have a strictly positive interest rate or currency swap exposure. In other words, less than half of the small- and medium-sized banks in our sample (strictly speaking: of the observations) use swaps.

In Table 6, we present variables relevant to the section about countermeasures. We group them in three categories, namely variables measuring the risk, income and other variables. The variables $B V L, B R$ and $I R R$ measure a bank's exposure to interest rate and credit risk. All risk variables are defined in such a way that a higher value implies more risk. In detail, these measures are defined as follows:

The variable $B V L$ gives the write-downs (= losses in book value) of bonds in the liquidity reserve as a consequence of a 200 bp upward shock to the interest rate level. Bonds in the liquidity reserve are treated as current assets and have to be written down if the market price is below the book value. We see a monotonic increase from the previous wave to the respective following waves. However, this need not be due to an increase in duration risk of the bonds. Another explanation is that the share of bonds whose prices are above the book value becomes smaller, the longer the low interest rate environment persists, because bonds with higher coupons mature and are replaced with bonds of lower coupons. This can be explained using the following example. Suppose a bank invests in a revolving manner in risk-free par-yield-bonds of $M=10$ years of maturity. Further, suppose the interest rate level suddenly goes down by 3 percentage points in $t_{0}$ (after the financial crisis, there was a rapid and sharp decline in the interest rate level), i.e., $\Delta_{0}=-3 \%$. As a consequence, the present value of this strategy increases by approximately 15 cent for every euro (see Memmel (2014)). For banks that balance their bonds at amortized costs, these gains in present value do not enter their balance sheet, but are hidden reserves. The further back the drop in interest rate level (at $t_{0}$ ) is in the past, the smaller are the remaining hidden reserves, because this passive trading strategy pays more in interest than corresponds to the then current interest rate level, so that the hidden reserves get smaller in the course of time. ${ }^{8}$ Under the above assumptions, the present value losses of banks' bond portfolios as a consequence of the $200 \mathrm{bp}$ upward shock remain the same in the three waves (namely: 10 cent per euro). Given these assumptions, it turns out that it becomes less and less possible to compensate the present value losses by liquidating the hidden reserves, the more time has passed since the downward shock in $t_{0}$, with the result that the reductions in the book value increase. ${ }^{9}$

\footnotetext{
7 The values of the upward scenario are multiplied by $-0.5=-100 / 200$.

8 It can be shown that the relationship is approximately quadratic with present time $t$ : hiddenreserves $(t) \approx$ $-\triangle_{0} \cdot\left(M-\left(t-t_{0}\right)\right)^{2} /(2 \cdot M)$. See Appendix 1, Eq. (17).

${ }^{9}$ Under the assumption that $t_{0}=2009$, the reductions in the book value of this strategy as a consequence of the 200 bp upward shock, i.e., $\Delta_{T}=2 \%$, are 6.25 cent in 2014, 8.65 cent in 2016 and 9.85 cent in 2018 per euro. See Appendix 1, Eq. (15).
} 


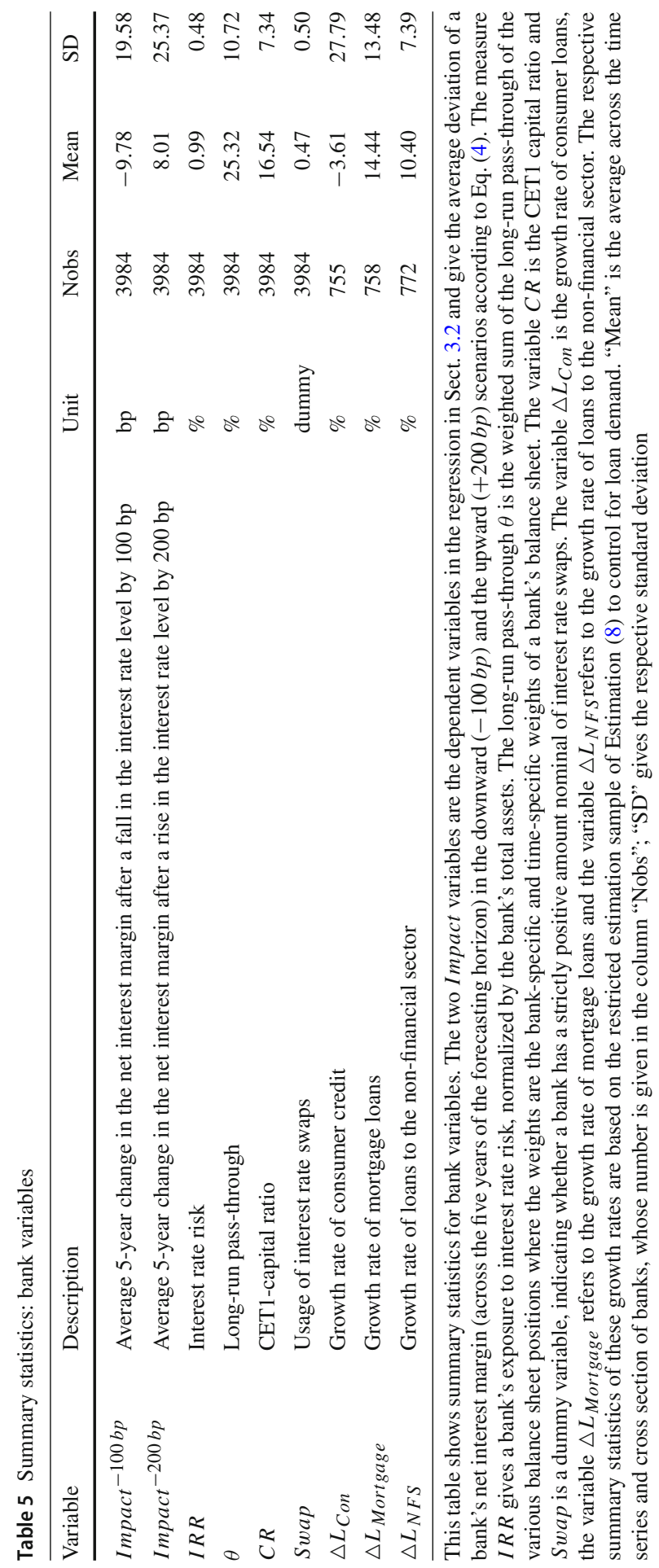




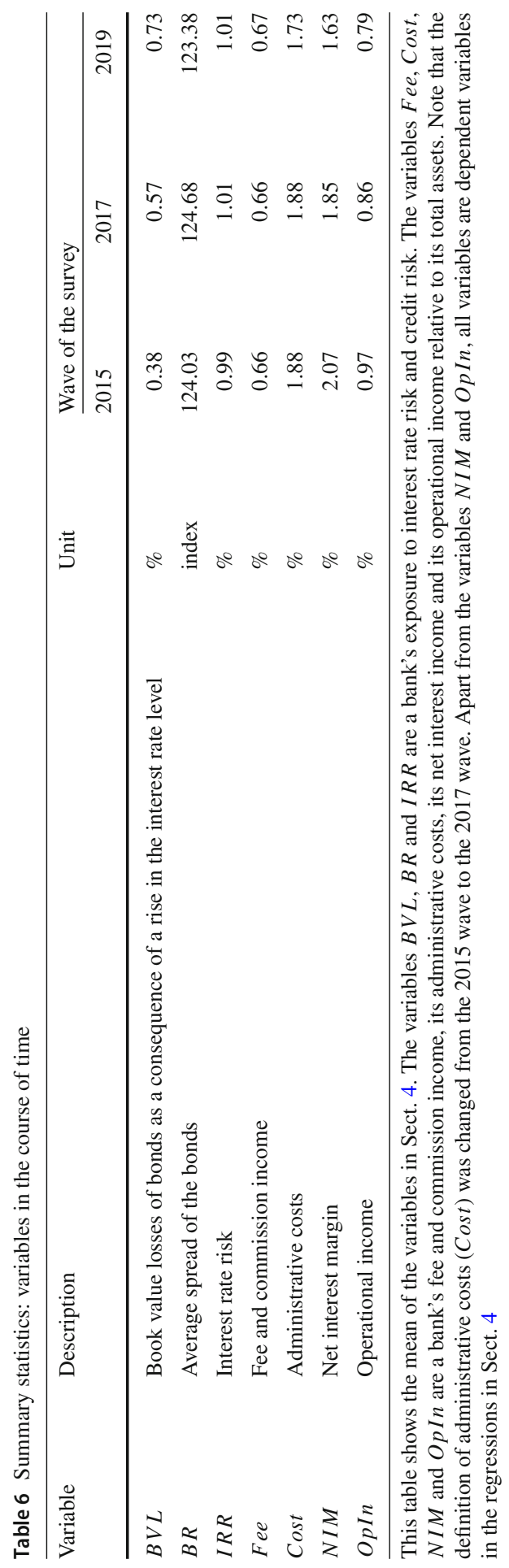


The variable $B R$ is an index that expresses the creditworthiness of a bank's bond holdings. It can be seen as a weighted sum of spreads for different rating classes:

$$
B R_{T, i}=\sum_{j=1}^{J} \operatorname{Spread}_{j} \cdot w_{T, j, i}
$$

where $\operatorname{spread}_{j}$ is a normalized spread for the rating class $j$, and $w_{T, i j}$ is the weight (based on market prices) of bonds of rating class $j$ at time $T$ in bank $i$ 's bond portfolio. Note that the variable Spread $_{j}$ has no time index $T$; it is defined with respect to the stress scenario of the 2019 wave.

The variable $I R R$ gives a bank's exposure to interest rate risk. It is defined as the change in the present value of a bank's banking book as a consequence of a $200 \mathrm{bp}$ parallel upward shift of the entire term structure (see also above and Table 5).

The variables $B V L, I R R, N I M, O p I n, F e e$ and Cost are standardized by a bank's total assets. Note that $O p I n$ and NIM are historical values and refer to the year before the respective wave of the survey.

In the summary statistics above, we exclude all banks that do not have a valid value for each variable shown in the table. In the regressions, we apply a mild outlier correction by removing the first and the 99 th percentiles of each variable.

\section{Interest income}

\subsection{Duration and interest rate level}

As for the duration of a changing interest rate regime, it is believed that the longer it persists, the stronger will be the impact, because only new business is affected and, as time goes by, more and more business is replaced. We measure the duration by the variable $t=1, \ldots, 5$, which gives the period (years) since the downward $j=-100 \mathrm{bp}$ or upward $j=+200 \mathrm{bp}$ shift in the interest rate level. To account for possible convex or concave relationships, we also add the duration $t$ as an quadratic term in regression (3):

$$
\begin{aligned}
C . N I M_{t, i}^{T, j}= & \alpha_{0}+\alpha_{1} \cdot t+\alpha_{2} \cdot t^{2}+ \\
& \beta_{0,2015} \cdot d_{2015}+\beta_{1,2015} \cdot d_{2015} \cdot t+\beta_{2,2015} \cdot d_{2015} \cdot t^{2}+ \\
& \beta_{0,2019} \cdot d_{2019}+\beta_{1,2019} \cdot d_{2019} \cdot t+\beta_{2,2019} \cdot d_{2019} \cdot t^{2}+\varepsilon_{t, i}
\end{aligned}
$$

with $C . N I M_{t, i}^{T, j}:=N I M_{t, i}^{T, j}-N I M_{t, i}^{T, 0}, T=2015,2017,2019$, bank $i=1, \ldots, N$ and $j=-100 \mathrm{bp},+200 \mathrm{bp} . d_{2015}$ and $d_{2019}$ denote dummy variables for the respective waves. There are 15 observations for each bank and each of the two scenarios: three times a forecast horizon of five years (as displayed in Tables 1 and 4).

According to the results displayed in Table 7, for every year's duration of the tightened low interest rate environment, the banks' $N I M$ reduces by 5.1 bp per 100 bp shock; for the upward scenario (+200 bp), we find an increase of 5.2 bp per year 


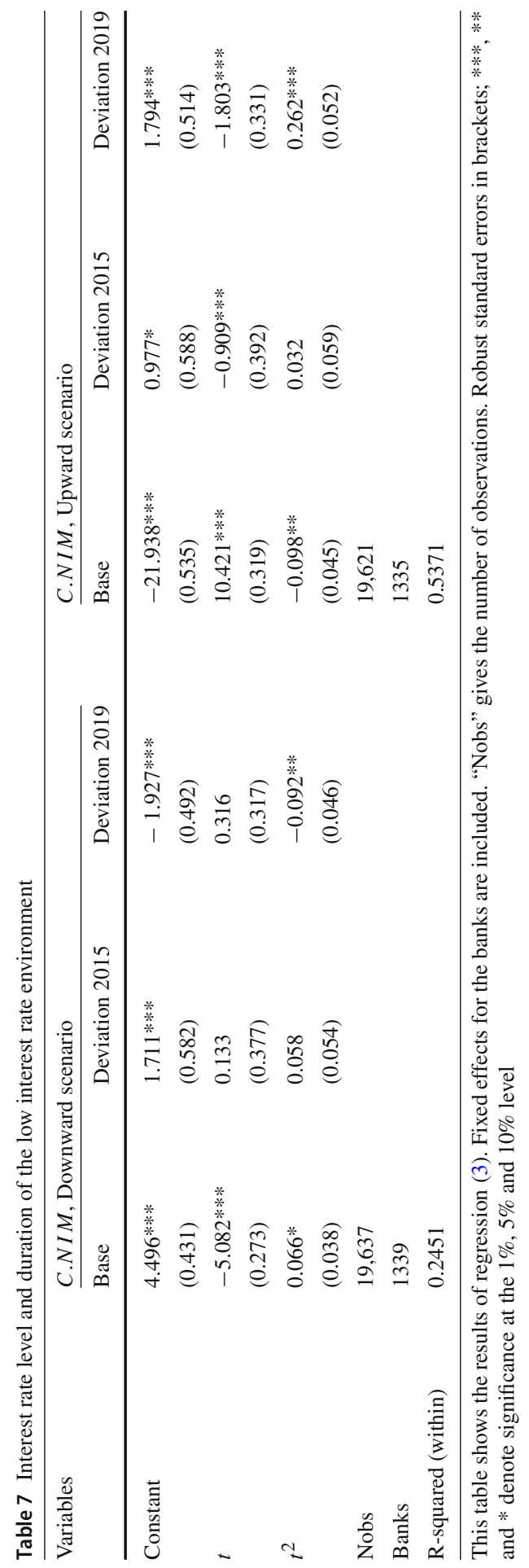


and 100 bp shock. This looks rather symmetric, i.e., a small increase in the interest rate level leads to a result of the same magnitude (only with the opposite sign) as a small decrease in the interest rate level. However, the change in the NIM in the +200 bp scenario can be much better explained by the regressors in regression (3) than the change in NIM in the downward scenario (-100 bp scenario), which can be seen by comparing the R-squared of $24.5 \%$ in the downward scenario and of $53.7 \%$ in the upward scenario. ${ }^{10}$

The relationships concerning the duration $t$ seem to be almost linear and only weakly convex or concave, i.e., the additional reduction or increase in NIM only slowly becomes stronger or weaker the longer the low interest rate environment persists. ${ }^{11}$

Busch and Memmel (2017) find that for short horizons, a decline in the interest rate level leads to an increase in the banks' $N I M$. We find this for the first year of the survey waves in 2015 and in 2017 (see Table 4), but not for any year in the 2019 wave.

In addition, for the $-100 \mathrm{bp}$ scenario, the deviation of N I M in 2017 was, on average, 1.7 bp worse compared to 2015 , but 1.9 bp better than in 2019 . This finding may lead to the conclusion that the $100 \mathrm{bp}$ drop in the interest rate level becomes more and more severe, the lower the relevant interest rate level for the banks is. With the help of the delta method, we test this hypothesis and look at the significance of the statistics $T S=\hat{\beta}_{0,2015} \cdot \hat{\beta}_{0,2019} /$ std, which turns out to be significant at the $1 \%$ level for the -100 bp scenario. ${ }^{12}$ For the +200 -bp-scenario, we do not find such a relationship.

Above, we have seen that the deviation of the net interest margin from the baseline (C.NIM) can be adequately described by a constant and a linear term for the time since the shock (sufficiently high $R^{2}$ and barely significant coefficients for the quadratic terms in Table 7). Therefore, to reduce the dimensionality, we define the variable $\operatorname{Impact}_{T, i}^{j}$ as

$$
\operatorname{Impact}_{T, i}^{j}=\frac{1}{5} \cdot \sum_{t=1}^{5} C \cdot N I M_{t, i}^{T, j},
$$

i.e., the average deviation of a bank's net interest margin $(N I M)$ over the five-year horizon as a consequence of a fall in the interest rate level of $100 \mathrm{bp}(j=-100 \mathrm{bp})$ or an increase in the interest rate level of $200 \mathrm{bp}(j=+200 \mathrm{bp})$. Below, we concentrate on the downward scenario $(j=-100 \mathrm{bp}$ ). We count the number of banks for which the downward shock was more severe in 2017 relative to 2015 , and in 2019 relative to 2017 (see Table 8). This was the case for 808 and 746 banks, respectively (out of 1,331 banks which participated in all three waves of the survey), which corresponds to $60.7 \%$ and $56.0 \%$. In both cases, these shares are statistically significantly greater than $1 / 2$. As for the impact on a bank's net interest margin in the two periods, we observe

\footnotetext{
10 When we regress the deviations in NIM in both scenarios on each other, we find that the relationship, measured by the $R^{2}$, is stronger by far in the 2015 wave than in the subsequent waves.

11 Note that in the downward scenario, the quadratic term for 2015 is significantly convex at the $1 \%$ level and at the $10 \%$ level for 2017. In the upward scenario, the quadratic term for 2017 is significantly concave at the 5\% level and for 2019 it is significantly convex at the $1 \%$ level.

12 We hypothesize that the test statistics $T S$ value is negative, i.e., that the deviations from the constant $\beta_{0,2015}$ and $\beta_{0,2019}$ have opposite signs. Note that this hypothesis includes the unlikely case that $\beta_{0,2015}$ is negative and $\beta_{0,2019}$ is positive. For the $-100 \mathrm{bp}$ scenario, we can reject the null hypothesis of a positive or zero test statistics TS at a p-value of $0.07 \%$. No rejection is possible for the $+200 \mathrm{bp}$ scenario.
} 
Table 8 Impact relative to the respective previous wave (downward scenario)

\begin{tabular}{lllll}
\hline Number of banks (share) & \multicolumn{4}{l}{ Worse in 2019 relative to $2017\left(X_{2}\right)$} \\
\hline Worse in 2017 relative to 2015 $\left(X_{1}\right)$ & & No & Yes & Sum \\
& No & $164(12.4 \%)$ & $359(26.9 \%)$ & $523(39.3 \%)$ \\
& Yes & $421(31.6 \%)$ & $387(29.1 \%)$ & $808(60.7 \%)$ \\
& Sum & $585(44.0 \%)$ & $746(56.0 \%)$ & $1331(100 \%)$
\end{tabular}

This table shows the number of banks for which the impact of the fall in the interest rate level (downward scenario) on their net interest margin was worse in the 2017 survey and in the 2019 survey compared to the respective previous survey

that there are fewer cases in which twice an improvement, i.e., $X_{1}=0 \wedge X_{2}=0$, or twice a deterioration, i.e., $X_{1}=1 \wedge X_{2}=1$, takes place than in the case of serial independence. This effect can be due to measures that a bank takes exactly once, either in the first period or in the second period, such as the abolition of negative rates for customer deposits (see Appendix 2). For instance, the share of banks with two deteriorations is $29.1 \%$; in the case of serial independence, we would expect $34.0 \%$ $(=0.607 * 0.560) .{ }^{13}$

\subsection{Bank-specific determinants}

The aim of this section is to explain the effect of the upward and downward scenarios on the net interest margins using bank-specific determinants. We concentrate on two determinants, namely the long-run pass-through $\theta$ and the exposure to interest rate risk $I R R$. For the long-run pass-through, we argue as follows. The traditional business model of banks consists of granting loans and collecting deposits, which are barely remunerated (if at all). ${ }^{14}$ This traditional business model yields a large mismatch between assets and liabilities regarding their long-run pass-through, because the deposits on the liability side tend to have a much lower long-run pass-through than the loans on the asset side. An extreme case would be a central bank whose assets (loans to banks) are tied to the (short-term) interest rate level and whose liabilities consist of banknotes, which are not remunerated at all. Therefore, we hypothesize that the larger a bank's asset-liability-pass-through mismatch, the more a downward shift in the interest rate level reduces its net interest margin. Hence, we expect a negative sign for $\gamma_{1}$. Regarding the exposure to interest rate risk $I R R$ we argue as follows: The more a bank is exposed to interest rate risk, the longer the former interest rate level is relevant on the asset-side (relative to the liability-side). Therefore, banks with a substantial exposure to interest rate risk benefit if there is a downward shift, i.e.,

\footnotetext{
13 For the case of two improvements, we observe a share of $12.4 \%$, but would expect $17.3 \%(=0.393$ * 0.440) in case of serial independence. Regarding Table 8, we test the hypothesis that the development from 2015 to 2017 is independent from the development from 2017 to 2019, which can be rejected at any reasonable confidence level.

14 Deposits from non-banks form a substantial part of banks' liabilities. However, the measure $\theta$, i.e., the long-run pass-through, is more comprehensive than the share of deposits. Therefore, we use the measure $\theta$ instead of the share of deposits. As expected, the results become more robust.
} 
the coefficient $\gamma_{2}$ is expected to be positive in the case of a downward shift. For the upward case, we expect the opposite signs for $\gamma_{1}$ and $\gamma_{2}$.

$$
\begin{aligned}
\operatorname{Impact}_{T, i}^{j}= & \alpha+\beta_{0,2015} \cdot d_{2015}+\beta_{0,2019} \cdot d_{2019}+\gamma_{1} \cdot \theta_{T, i}+\gamma_{2} \cdot I R R_{T, i} \\
& +\delta_{1} \cdot C R_{T, i}+\delta_{2} \cdot \operatorname{Swap}_{T, i}+\varepsilon_{T, i}
\end{aligned}
$$

with point in time $T=2015,2017,2019$, scenario $j=-100 \mathrm{bp},+200 \mathrm{bp}$, bank $i=1, \ldots, N$, the share of bank $i$ 's long-run pass-through $\theta_{T, i}$ and its interest rate risk $I R R_{T, i} . d_{2015}$ and $d_{2019}$ denote dummy variables for the respective surveys. In addition, regression (5) is not only estimated as a panel, but also as a cross-sectional regression where time series averages (over the three points in time) are calculated for each variable. We also estimate a cross-sectional regression to account for the empirical finding that most of the variation of the variables under investigation is between the banks and not in the time dimension (see Memmel (2018)). Note that as the main explanatory variables $I R R$ and $\theta$ are only available once in each of the three waves (and not five times), we resort to the summary dependent variable impact (instead of C.NIM).

The results are shown in Table 9. ${ }^{15}$ We find a dependency between the long-term pass-through (especially when looking at the cross-sectional regressions in columns 2 and 4) and the effect of a change in interest rate levels. When the interest rate level goes down, the net interest margin decreases, the more a bank's business model implies a large long-run pass-through. The same is true when the interest rate level goes up. Here, we find this effect not only in the cross section, but in the panel specification as well. Regarding the exposure to interest rate risk $I R R$, we find that the coefficients have the expected signs and are significant, apart from the panel specification in the downward scenario. We assume that the long-run pass-through $\theta$ is difficult to change for a bank (as it strongly depends on the bank's business model). Nevertheless, this bank can soften the impact of changes in the interest rate level on its mid-term net interest income by exposing itself to interest rate risk (which may be easily changed, for instance, by contracting appropriate swap positions).

In addition, it seems as if the upward scenario is much better explained than the downward scenario, which can be seen by comparing the respective R-squared $(9.5 \%$ vs $3.2 \%$ and $23.9 \%$ vs $2.0 \%$ ). This result is already noted in Sect. 3.1. Comparing the results of the panel and the cross section, we see, especially in the upward scenario, that the relevant coefficients $\theta$ and $I R R$ have the same sign and a similar magnitude.

\section{Countermeasures}

\subsection{Risk-taking}

If banks want or have to offset a reduction in their incomes, one possibility is to invest more in risky securities or to increase their exposure to interest rate risk, thereby earning

\footnotetext{
15 Note that this regression does not show causal relationships, but correlations between the dependent and explanatory variables.
} 
Table 9 Bank-specific determinants

\begin{tabular}{|c|c|c|c|c|}
\hline \multirow[t]{2}{*}{ Variables } & \multicolumn{2}{|c|}{ Impact, Downward scenario } & \multicolumn{2}{|c|}{ Impact, Upward scenario } \\
\hline & Panel & Cross section & Panel & Cross section \\
\hline \multirow[t]{2}{*}{$d_{2015}$} & \multicolumn{2}{|l|}{$2.515 * * *$} & \multicolumn{2}{|l|}{-0.157} \\
\hline & \multicolumn{2}{|l|}{$(0.630)$} & \multicolumn{2}{|l|}{$(0.503)$} \\
\hline \multirow[t]{2}{*}{$d_{2019}$} & \multicolumn{2}{|l|}{$-1.882 * * *$} & \multicolumn{2}{|l|}{$-1.713 * * *$} \\
\hline & \multicolumn{2}{|l|}{$(0.475)$} & \multicolumn{2}{|l|}{$(0.445)$} \\
\hline \multirow[t]{2}{*}{$\theta$} & -0.045 & $-0.130 * * *$ & $0.560 * * *$ & $0.461 * * *$ \\
\hline & $(0.110)$ & $(0.038)$ & $(0.106)$ & $(0.052)$ \\
\hline \multirow[t]{2}{*}{$I R R$} & $1.16 \mathrm{t} 4$ & $2.494 * * *$ & $-14.829 * * *$ & $-21.143^{* * *}$ \\
\hline & $(1.197)$ & $(0.942)$ & $(1.246)$ & $(1.268)$ \\
\hline \multirow[t]{2}{*}{$C R$} & -0.136 & -0.086 & 0.217 & $0.560 * * *$ \\
\hline & $(0.228)$ & $(0.102)$ & $(0.186)$ & $(0.138)$ \\
\hline \multirow[t]{2}{*}{ Swap } & -0.561 & $1.618 * *$ & 0.793 & 1.272 \\
\hline & $(1.338)$ & $(0.675)$ & $(1.126)$ & $(0.842)$ \\
\hline \multirow[t]{2}{*}{ Constant } & $-7.662 *$ & $-8.653 * * *$ & 4.833 & $7.512 * * *$ \\
\hline & $(4.062)$ & $(1.737)$ & $(3.627)$ & $(2.377)$ \\
\hline Nobs & 3691 & 1133 & 3691 & 1133 \\
\hline Banks & 1300 & & 1300 & \\
\hline R-squared & 0.0317 & 0.0202 & 0.0950 & 0.2386 \\
\hline
\end{tabular}

This table shows the results of regression (5); in the panel regressions (second and fourth column), fixed effects for the banks are included. dependent variable is always Impact as defined in Eq (4). "Nobs" gives the number of observations. Robust standard errors in brackets; $* * * * *$ and $*$ denote significance at the $1 \%, 5 \%$ and $10 \%$ level. Cross section means averages over the three surveys

risk premiums (see, for example, Wong (1997) and Rajan (2005)). This relationship is expressed in Eq. (6).

$$
\begin{aligned}
& \triangle \operatorname{Risk}_{T, i}=\alpha+\beta \cdot \triangle \operatorname{Risk}_{T-1, i} \\
& +\gamma_{1} \cdot \Delta \text { Income }_{T-1, i}+\gamma_{2} \cdot \text { LowCap }_{T-1, i}+\gamma_{3} \cdot \text { Outlier }_{T-1, i} \\
& +\gamma_{4} \cdot \text { LowCap } \triangle \text { Income }_{T-1, i}+\gamma_{5} \cdot \text { Outlier } \triangle \text { Income }_{T-1, i} \\
& +\delta_{1} \cdot C R_{T-1, i}+\delta_{2} \cdot \operatorname{Swap}_{T-1, i}+\varepsilon_{T, i}
\end{aligned}
$$

where $\triangle R i s k_{T, i}$ is either the change (relative to the previous survey) in mark-tomarket losses of bonds in the liquidity reserve (Liquititätsreserve) as a consequence of an increase in the risk interest rate level $(\triangle B V L)$ or the change in the rating of these bonds $(\triangle B R)$ or the change in the bank's exposure to interest rate risk $(\triangle I R R)$. Note that the risk measures $B V L$ and $B R$ only encompass the banks' bond holdings, which account for about $20 \%$ of total assets (see Dräger et al. (2021)). Only the measure $I R R$ considers the whole banking book (including positions on the liability-side such as deposits, but leaving aside the trading book, if it exists). We resort to the measures $B V L$ and $B R$, because it seems plausible that banks steer their risk-taking by changing their bond positions rather than by changing the riskiness of their loans. $\triangle$ Income is 
either the change (relative to the previous wave of the survey) in the net interest margin $\triangle N I M$ or the change in the operational income (before impairments, normalized by total assets) $\triangle O p I n$. The dummy variable Outlier, which takes on the value one if a bank exceeds a certain threshold concerning its exposure to interest rate risk, was inserted, as Memmel (2020) finds that the regulation has a strong impact on a bank's exposure to interest rate risk. The variable Low Cap is a dummy variable too and takes the value one if bank $i$ 's capital ratio is among the lowest 5 percent in time $T$. Note that due to the time structure- the change in the respective incomes $\triangle$ Income and all other variables are lagged by two years, i.e., the period between two waves of the survey - the time dimension of the three waves decreases to one and there remains a pure cross-sectional regression, whose results are displayed in Table 10.

On the basis of these results, we do not find evidence that banks generally increase their risk by increasing the duration of the bonds in their liquidity reserve $(\triangle B V L)$, by investing in bonds with lower creditworthiness $(\triangle B R)$ or by increasing their exposure to interest rate risk $(\triangle I R R)$, after a drop in their net interest income $(\triangle N I M)$ or in their operational profits $(\triangle O p I n)$. In column (6), we even see a highly significant positive sign in front of $\triangle O P I n$, meaning that a drop in operational income is associated with a reduction in the exposure to interest rate risk. Nevertheless, it seems as if poorly capitalized banks react differently to normally capitalized banks with respect to changes in the creditworthiness of their bond portfolio: Whereas normally capitalized banks do not lower the creditworthiness in their bond portfolio after a drop in their income, we find such a reaction for poorly capitalized banks (significant coefficients in front of the (lagged) interaction term l.LowC $\triangle$ Income in columns 3 and 4).

In addition, we find evidence regarding risk-taking, namely that where a bank numbers among the banks with elevated exposure to interest rate risk (dummy variable Outlier $=1$ ), we see that such banks reduce their subsequent exposure to interest rate risk (negatively significant coefficients in front of $l$.Outlier in columns 5 and 6) and increase the subsequent underlying credit risk of their bond holdings (positively significant coefficient in front of l.Outlier in columns 3 and 4). Note that this shift in the risk composition is not linked to a drop in the income.

\subsection{Other revenue sources and costs}

Looking at NIM and OpIn in Table 6, we see that the net interest margin, which is a major component of operational income, reduces by more than the operational income. This may be evidence that banks look for other sources of revenues and decrease administrative costs in a low interest rate environment. We analyze this using the following regression at bank level:

$$
\begin{aligned}
\operatorname{Other~}_{T, i}= & \alpha+\beta \cdot \Delta \text { Other }_{T-1, i}+\gamma \cdot \Delta \text { Income }_{T-1, i} \\
& +\delta_{1} \cdot C R_{T-1, i}+\delta_{2} \cdot \operatorname{Swap}_{T-1, i}+\varepsilon_{T, i}
\end{aligned}
$$

where $\triangle O$ ther $_{T, i}$ is either the change (relative to the previous survey) in fee and commission income $(\triangle F e e)$ or in administrative costs $(\triangle C o s t)$ and $\triangle$ Income is either the change (relative to the previous survey) in the net interest margin $(\triangle N I M)$ 


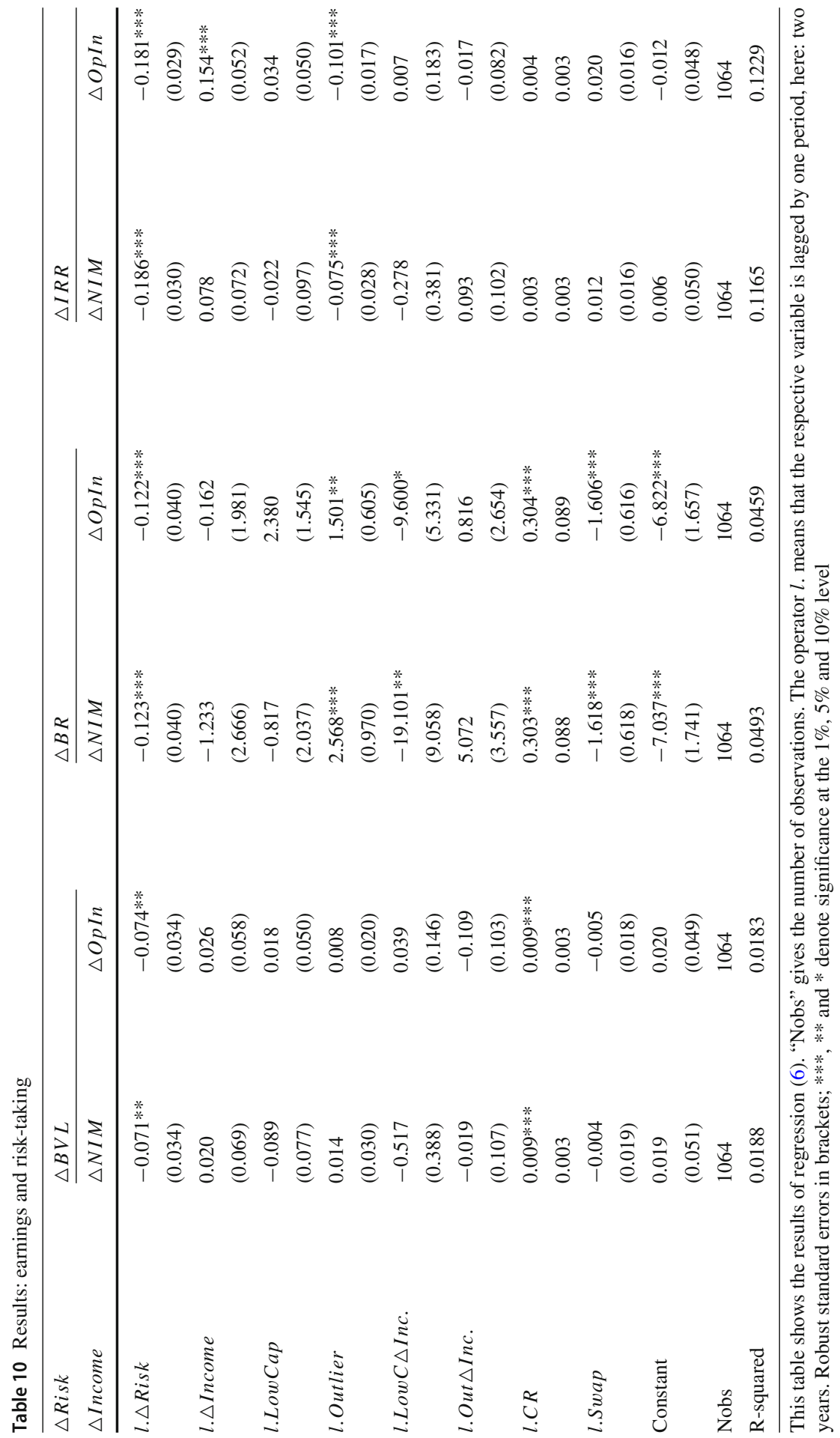


Table 11 Results: earnings and other components

\begin{tabular}{|c|c|c|c|c|}
\hline \multirow{2}{*}{$\begin{array}{l}\triangle \text { Other } \\
\triangle \text { Income }\end{array}$} & \multicolumn{2}{|l|}{$\triangle F e e$} & \multicolumn{2}{|l|}{$\triangle \operatorname{Cos} t$} \\
\hline & $\triangle N I M$ & $\triangle O p I n$ & $\triangle N I M$ & $\triangle O p I n$ \\
\hline l. $\triangle$ Other & $\begin{array}{l}-0.099 * * \\
(0.040)\end{array}$ & $\begin{array}{l}-0.084 * * \\
(0.041)\end{array}$ & & \\
\hline l. $\triangle$ Income & $\begin{array}{l}-0.010 \\
(0.013)\end{array}$ & $\begin{array}{l}-0.038 * * * \\
(0.011)\end{array}$ & $\begin{array}{l}0.075 * * * \\
(0.027)\end{array}$ & $\begin{array}{l}0.078 * * * \\
(0.027)\end{array}$ \\
\hline l.CR & $\begin{array}{l}0.002 * * * \\
(0.001)\end{array}$ & $\begin{array}{l}0.001 * * \\
(0.001)\end{array}$ & $\begin{array}{l}0.004 * * * \\
(0.001)\end{array}$ & $\begin{array}{l}0.005^{* * * *} \\
(0.001)\end{array}$ \\
\hline l.Swap & $\begin{array}{l}-0.005 \\
(0.004)\end{array}$ & $\begin{array}{l}-0.005 \\
(0.004)\end{array}$ & $\begin{array}{l}0.020 * * \\
(0.008)\end{array}$ & $\begin{array}{l}0.024 * * * \\
(0.008)\end{array}$ \\
\hline Constant & $\begin{array}{l}-0.004 \\
(0.011)\end{array}$ & $\begin{array}{l}-0.002 \\
(0.011)\end{array}$ & $\begin{array}{l}-0.204 * * * \\
(0.024)\end{array}$ & $\begin{array}{l}-0.220 * * * \\
(0.023)\end{array}$ \\
\hline Nobs & 1162 & 1162 & 1162 & 1162 \\
\hline R-squared & 0.0209 & 0.0313 & 0.0243 & 0.0274 \\
\hline
\end{tabular}

This table shows the results of regression (7). The operator $l$. means that the respective variable is lagged by one period, here: two years, i.e., all explanatory variables are lagged by two years. "Nobs" gives the number of observations. Robust standard errors in brackets; ***, ** and * denote significance at the $1 \%$, $5 \%$ and $10 \%$ level

or the change in the operational income (before impairments, normalized with total assets, $\triangle O p I n)$. The results are displayed in Table 11 . There are three main results: (i) a drop in income makes banks increase their fee and commissions income and reduce their administrative costs; (ii) as shown by the R-squared (3.1\% vs. $2.1 \%$ and $2.7 \%$ vs. $2.4 \%$ ) and by the significance of the coefficients, the operational income seems to be more informative than the net interest income; (iii) a drop in operational income makes banks increase their fee and commission income and reduce costs. The combined effect of both is about 11.6 cent $=3.8$ cent +7.8 cent for every euro of change in the operational income, i.e., the net effect of a reduction in the interest rate level on profitability is negative.

\subsection{Composition of the loan portfolio}

So far, we have derived the results under the assumption of a static balance sheet, which implies that maturing loans are replaced by equivalent loans so that total assets and their composition remain constant. But banks can mitigate a reduction in the margins for loans by granting more loans or by changing the composition of their loan portfolio. We investigate whether reductions in the operational income and the net interest margin are associated with future changes in the composition of the loan portfolio.

For this purpose, we distinguish between consumer loans $L_{C o n}$, mortgage loans $L_{M o r t g a g e}$ and total loans to the non-financial sector $L_{N F S}$. The dependent variables are defined as growth rates of the respective loan types. Since we are interested in banks' responses to reductions in income, it is crucial to account for loan demand. 
Given the structure of our data set, we exploit information on the geographical location of banks to create a loan demand control variable. This control variable captures the contemporary credit growth of all other banks operating in the same district. Furthermore, to operationalize our identification strategy, we restrict our sample to regional banks and include only districts where at least two regional banks are active in the respective loan type market. This approach enables us to account for regional credit demand effects.

Similar to Eqs. (6) and (7), we employ the following additional control variables: We again include both dummy variables Outlier and LowCap, the CET1 capital ratio $(C R)$, the long-run interest rate pass-through $\theta$, the dummy variable Swap, fee and commission income to total assets ( Fee ), and administrative costs to total assets $(\operatorname{Cos} t)$. Since we use loan type growth rates, we further control for bank size $(\ln ($ Assets $))$ as well as contemporaneous asset growth $(\Delta$ Assets $)$. Apart from the credit demand control variable and asset growth, all control variables are lagged including the lagged credit type growth. The corresponding estimation equation is depicted by Eq. (8):

$$
\begin{aligned}
\operatorname{Loan}_{T, i}= & \alpha+\beta_{1} \cdot \triangle \operatorname{Loan}_{T-1, i}+\beta_{2} \cdot \triangle \text { Income }_{T-1, i} \\
& +\beta_{3} \cdot \triangle \operatorname{LoanDCtrl}_{T, I(i)}+\gamma \cdot \text { OtherControls } \\
T-1, i & +\varepsilon_{T, i},
\end{aligned}
$$

where $I(i)$ denotes the average of all banks within the respective district of bank $i$, and thus, $\triangle \operatorname{Loan~} D C \operatorname{trl}_{T, I(i)}$ is our respective regional loan demand control variable. Table 12 displays the corresponding results of this analysis.

Overall, we find that banks respond to a decrease in the net interest margin by expanding their mortgage-based lending and reducing consumer lending. However, overall total loans to the non-financial sector remain unchanged. Hence, the shift from consumer to mortgage-based lending can be rationalized by a preferential risk-return trade-off relative to consumer loans. However, this result only applies to the change in the net interest margin where the effect is statistically significant at least at the 5 percent level. In contrast, we do not find such an effect for operational income. This finding provides evidence that banks consider the net interest margin rather than operational income when adjusting credit supply.

\section{Conclusion}

Data from three consecutive waves of a quantitative survey enable us to understand the dynamics of banks' net interest income and their behavioral changes as a consequence of a prolonged low interest environment. We find that the net interest margin decreases by $5 \mathrm{bp}$ for every additional year since a downward shift of $100 \mathrm{bp}$ in the interest rate level. Taking into account the immediate changes, the results imply a change in banks' net interest margins after the horizon of five years of around 20 bp per 100 bp change in the interest rate level, which seems to be in line with an average bank long-run passthrough of 25 bp per 100 bp of shock. At bank level, we find that a bank's exposure to interest rate risk softens the risk of changes in the net interest margin as a consequence of changes in the interest rate level. 


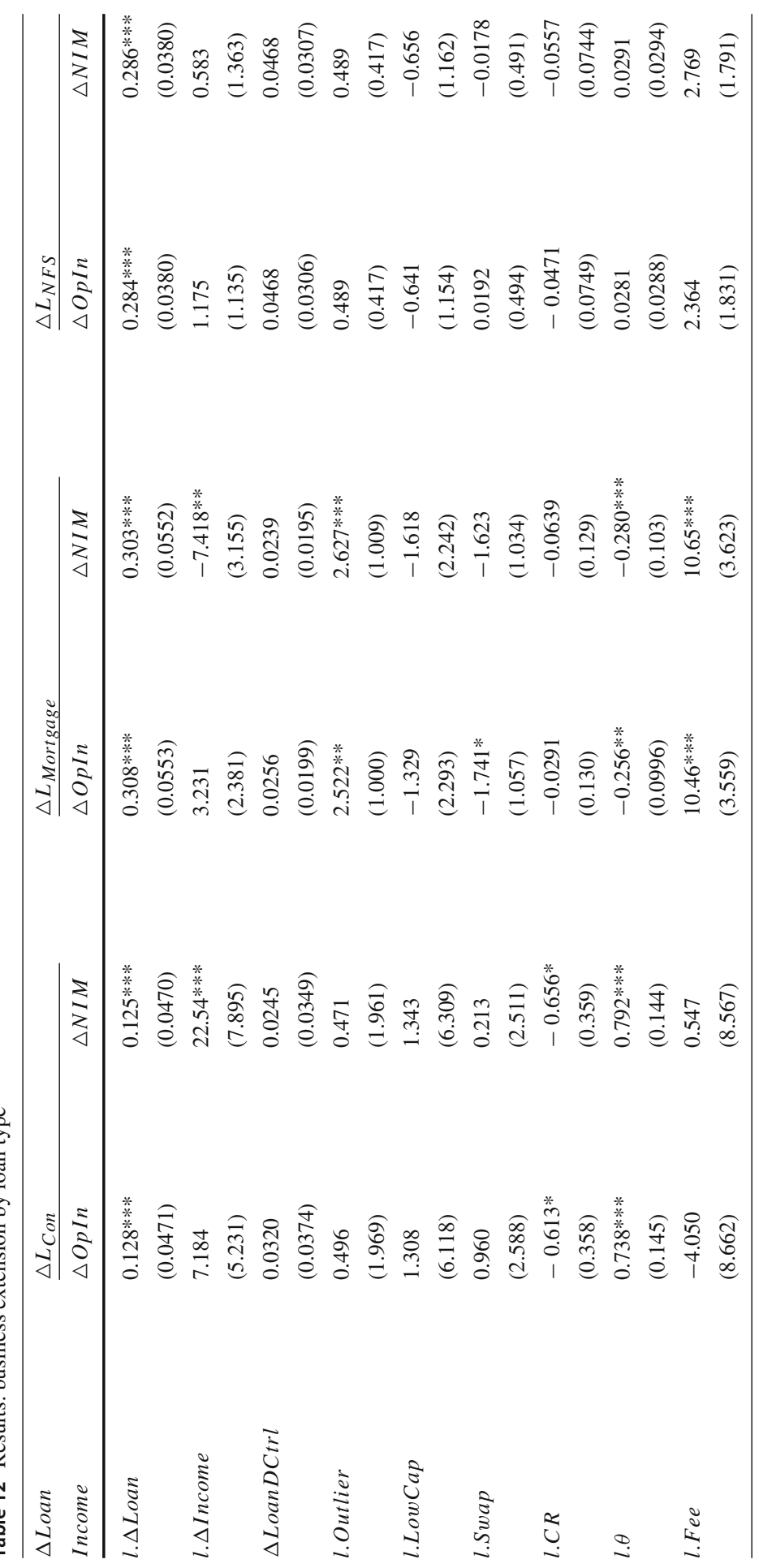




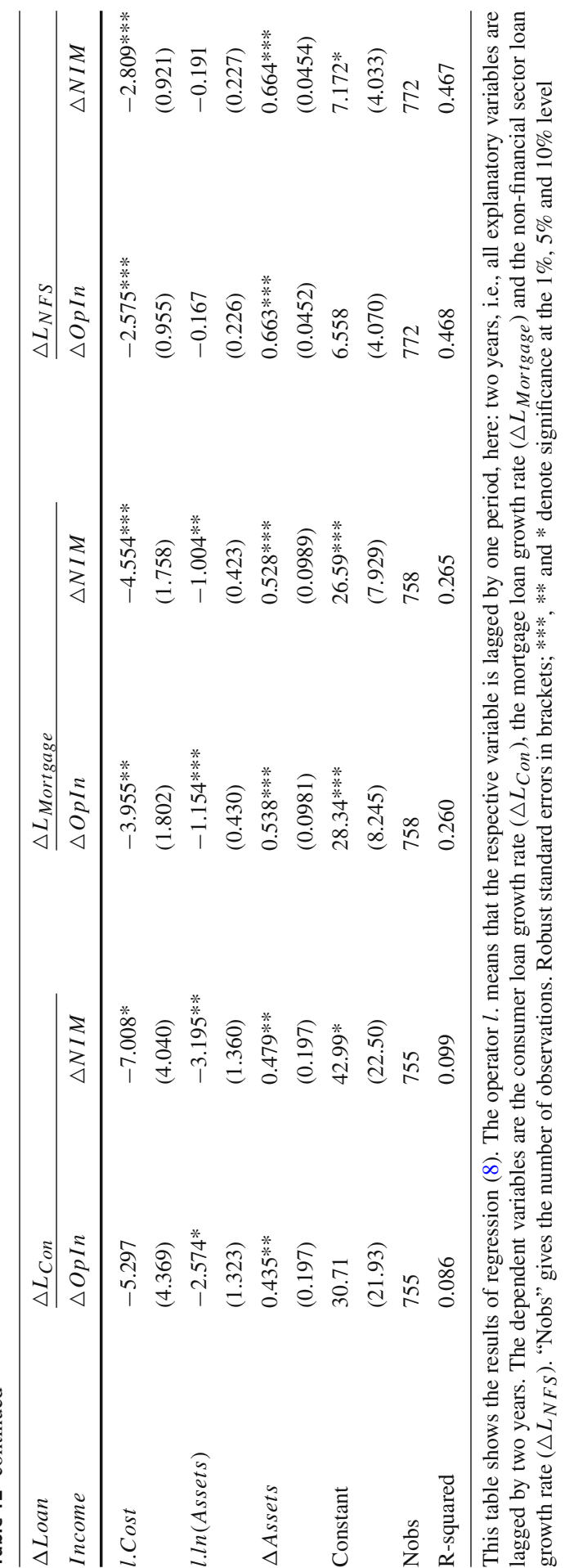


As regards risk-taking in connection with low interest rates and declining operational income, we find significant results only for poorly capitalized banks concerning the credit risk in their liquidity reserve. Also, we document a shift in the composition of risks for those banks that are already heavily exposed to interest rate risk, as they choose to enlarge their credit risk in the bond holdings. In addition, we see that banks which experienced a decline in their operational income not only increase their fee and commission income, but also reduce their administrative costs where such countermeasures compensate for only a small part of the reduction in income. Furthermore, there is evidence that banks shift their lending to mortgage loans after a decline in their net interest margin.

It seems as if the average bank can cope with the low interest rate environment, since increased risk-taking is only found for poorly capitalized banks, and increases in fee income, cost-cutting as well as changes in the lending composition may help to mitigate interest income reductions. In addition, we observe that banks that did not perform well in a survey wave tend to perform better in the subsequent wave (and vice versa), which prevents extreme developments for the average bank. However, one has to bear in mind that we analyze income variables before valuation. Little can be said about cases in which the average bank not only has to face the challenges of the low interest rate environment, but also, say, increases in credit losses.

Although the data the banks provide are quality-assured, we ultimately have to rely on the banks' assessment. Therefore, future research projects should incorporate back-testing and challenge banks' forecast abilities.

Acknowledgements The authors would like to thank an anonymous referee as well as the participants in the Bundesbank's research seminar (Frankfurt, 2020) and in the Annual Conference of the Verein für Socialpolitik (2021) for their helpful comments.

Funding Open Access funding enabled and organized by Projekt DEAL.

\section{Declarations}

Conflict of interest The views expressed in this paper are those of the authors and do not necessarily reflect the opinions of the Deutsche Bundesbank.

Open Access This article is licensed under a Creative Commons Attribution 4.0 International License, which permits use, sharing, adaptation, distribution and reproduction in any medium or format, as long as you give appropriate credit to the original author(s) and the source, provide a link to the Creative Commons licence, and indicate if changes were made. The images or other third party material in this article are included in the article's Creative Commons licence, unless indicated otherwise in a credit line to the material. If material is not included in the article's Creative Commons licence and your intended use is not permitted by statutory regulation or exceeds the permitted use, you will need to obtain permission directly from the copyright holder. To view a copy of this licence, visit http://creativecommons.org/licenses/by/4.0/. 


\section{Appendix}

\section{Appendix 1}

In this appendix, we want to show how the present value $P V_{T S}$ of a passive trading strategy evolves after changes in the interest rate level. This passive trading strategy consists in investing in par-yield risk-free bonds of maturity $M$ in a revolving manner, i.e., the principal of the maturing bonds is continuously reinvested (at the rate of $1 / M$ ) in the then current par-yield bond. By contrast, the interest payments are taken out.

Let $P V(c, r, M)$ be the present value of a bullet bond with coupon $c$, interest rate level (of a flat term structure) $r$ and maturity $M$.

$$
P V(c, r, M)=\frac{c}{r}+\left(1-\frac{c}{r}\right) \cdot \exp (-r M)
$$

For the interest rate level $r$, we assume the following:

$$
r(t)= \begin{cases}c_{S} & \text { for } t<t_{0} \\ c_{S}+\Delta_{0} & \text { for } t_{0} \leq t<T \\ c_{S}+\Delta_{0}+\Delta_{T} & \text { for } t=T\end{cases}
$$

Accordingly, the coupons of risk-free par-yield bonds are $c_{S}$ (for $t<t_{0}$ ), $c_{0}=$ $c_{S}+\Delta_{0}\left(\right.$ for $\left.t_{0} \leq t<T\right)$ and $c_{T}=c_{S}+\Delta_{0}+\Delta_{T}$ (for $t=T$ ).

In $t_{0} \leq T<M+t_{0}$, the portfolio of this trading strategy consists of bonds with coupon $c_{S}$ (share: ${ }^{16} 1-\frac{T-t_{0}}{M}$ ) and of bonds with coupon $c_{0}$ (share: $\frac{T-t_{0}}{M}$ ):

$$
P V_{T S}(T)=\frac{1}{M} \int_{o}^{M-\left(T-t_{0}\right)} P V\left(c_{S}, r, m\right) d m+\frac{1}{M} \int_{M-\left(T-t_{0}\right)}^{M} P V\left(c_{0}, r, m\right) d m
$$

Combining Eqs. (9) and (11), we obtain for the two summands above the following expressions (with $\tau:=T-t_{0}$ ):

$$
\begin{aligned}
& \frac{1}{M} \int_{0}^{M-\tau} P V\left(c_{S}, r, m\right) d m=\left(1-\frac{\tau}{M}\right) \\
& +\left(\Delta_{0}+\Delta_{T}\right) \frac{1-r(M-\tau)-\exp (-r(M-\tau))}{M r^{2}} \\
& \frac{1}{M} \int_{M-\tau}^{M} P V\left(c_{0}, r, m\right) d m=\frac{\tau}{M} \\
& +\Delta_{T} \frac{-r \tau+\exp (-r(M-\tau))-\exp (-r M)}{M r^{2}}
\end{aligned}
$$

\footnotetext{
16 Measured at initial values.
} 
Summing up Eqs. (12) and (13), we obtain

$$
P V_{T S}(T)=1+\Delta_{0} \frac{1-r(M-\tau)-\exp (-r(M-\tau))}{M r^{2}}+\Delta_{T} \frac{1-r M-\exp (-r M)}{M r^{2}}
$$

and for small $r$, we obtain

$$
\lim _{r \rightarrow 0} P V_{T S}(T)=1-\Delta_{0} \frac{(M-\tau)^{2}}{2 M}-\Delta_{T} \frac{M}{2} .
$$

For an arbitrary value $t \leq T$, we obtain

$$
P V_{T S}(t)=\left\{\begin{array}{cl}
1 & \text { for } t<t_{0} \\
1+\Delta_{0} \frac{1-r\left(M-\left(t-t_{0}\right)\right)-\exp \left(-r\left(M-\left(t-t_{0}\right)\right)\right)}{M r^{2}} & \text { for } t_{0} \leq t<T \\
\text { Equation (14) } & \text { for } t=T
\end{array} .\right.
$$

The corresponding relationship to Eq. (16) for small $r$ is

$$
\lim _{r \rightarrow 0} P V_{T S}(t)=\left\{\begin{array}{cl}
1 & \text { for } t<t_{0} \\
1-\Delta_{0} \frac{\left(M-\left(t-t_{0}\right)\right)^{2}}{2 M} & \text { for } t_{0} \leq t<T \\
\text { Equation }(15) & \text { for } t=T
\end{array}\right.
$$

\section{Appendix 2}

In this appendix, we want to show that the probability of extreme outcomes in the waves (i.e., two deteriorations or two improvements in the average deviation of the net interest margin (see Eq. (4)) is lower in the case of the model in this appendix than in the case of serial independence. Let $X_{1}$ and $X_{2}$ be random variables that take the value 1 if the average deviation of the net interest margin (Impact) of a bank worsens in the 2017 wave relative to the wave of the survey in 2015 and in the 2019 wave relative to the wave of the survey in 2017 and zero otherwise.

$$
\begin{aligned}
& X_{i}=\left\{\begin{array}{l}
0 \quad \text { with } \operatorname{Pr}\left(X_{i}=0\right)=1-p_{i} \\
1 \quad \text { with } \operatorname{Pr}\left(X_{i}=1\right)=p_{i}
\end{array}\right. \\
& p_{1}=\bar{p}_{1}+\eta
\end{aligned}
$$

and

$$
p_{2}=\overline{p_{2}}+\gamma-\eta
$$

with

$$
\eta= \begin{cases}0 & \text { with } \operatorname{Pr}(\eta=0)=1 / 2 \\ \gamma & \text { with } \operatorname{Pr}(\eta=\gamma)=1 / 2\end{cases}
$$

The random variable $\eta$ takes on 0 or $\gamma$, depending on whether an action, which needs to be taken exactly once, such as the decision to not remunerate deposits at a 
negative rate, is carried out in the first period (i.e., from 2015 to 2017) or in the second period (i.e., from 2017 to 2019).

Using the assumption that $X_{1}$ and $X_{2}$ are independent given $\eta$ and Eqs. (18) to (21), we obtain:

$$
\begin{aligned}
\operatorname{Pr}\left(X_{1}=1 \wedge X_{2}=1\right)= & 1 / 2 \cdot \operatorname{Pr}\left(X_{1}=1 \wedge X_{2}=1 \mid \eta=0\right) \\
& +1 / 2 \cdot \operatorname{Pr}\left(X_{1}=1 \wedge X_{2}=1 \mid \eta=\gamma\right) \\
= & 1 / 2 \cdot \overline{p_{1}} \cdot\left(\overline{p_{2}}+\gamma\right)+1 / 2 \cdot\left(\overline{p_{1}}+\gamma\right) \cdot \overline{p_{2}} \\
= & \overline{p_{1}} \cdot \overline{p_{2}}+1 / 2 \cdot \gamma \cdot\left(\overline{p_{2}}+\bar{p}_{1}\right)
\end{aligned}
$$

We define the deviation $D$ as the difference in the probability given in Eq. (22) and the probability of independence of $X_{1}$ and $X_{2}$ :

$$
\begin{aligned}
D & :=\operatorname{Pr}\left(X_{1}=1 \wedge X_{2}=1\right)-\operatorname{Pr}\left(X_{1}=1\right) \cdot \operatorname{Pr}\left(X_{2}=1\right) \\
& =-1 / 4 \gamma^{2}
\end{aligned}
$$

which is always negative for strictly positive values of $\gamma$, meaning that there are fewer banks which have a deterioration in their net interest income in each of the two comparisons than in case of independence. The same argumentation applies for the case $X_{1}=0 \wedge X_{2}=0$.

\section{References}

Albertazzi, U., Gambacorta, L.: Bank profitability and the business cycle. J. Financ. Stab. 5(4), 393-409 (2009)

Alessandri, P., Nelson, B.: Simple banking: profitability and the yield curve. J. Money Credit Bank. 47(1), 143-175 (2015)

Altunbas, Y., Gambacorta, L., Marquez-Ibanez, D.: Does monetary policy affect bank risk? Int. J. Cent. Bank. 10, 95-135 (2014)

Basten, C., Mariathasan, M.: How banks respond to negative interest rates: evidence from the Swiss exemption threshold. CESifo Working Papers 6901 (2018)

Bikker, J.A., Vervliet, T.M.: Bank profitability and risk-taking under low interest rates. Int. J. Finance Econ. 23, 3-18 (2017)

Boungou, W.: Negative interest rates policy and banks' risk-taking: empirical evidence. Econ. Lett. 186, 108760 (2020)

Brei, M., Borio, C., Gambacorta, L.: Bank intermediation activity in a low interest rate environment. Bank for International Settlements Working Papers (2019)

Busch, R., Drescher, C., Memmel, C.: Bank stress testing under different balance sheet assumptions. Discussion Paper 07/2017, Deutsche Bundesbank (2017)

Busch, R., Memmel, C.: Banks' net interest margin and the level of interest rates. Credit Cap. Mark. 50(3), 363-392 (2017)

Chaudron, R.F.: Bank's interest rate risk and profitability in a prolonged environment of low interest rates. J. Bank. Finance 89, 94-104 (2018)

Claessens, S., Coleman, N., Donnelly, M.: "Low-For-Long" interest rates and banks' interest margins and profitability: cross-country evidence. J. Financ. Intermed. 35, 1-16 (2018)

Delis, M.D., Kouretas, G.P.: Interest rates and bank risk-taking. J. Bank. Finance 35, 840-855 (2011)

Dräger, V., Heckmann-Draisbach, L., Memmel, C.: Interest and credit risk management in German banks: evidence from a quantitative survey. Ger. Econ. Rev. 22(1), 163-95 (2021)

Heider, F., Saidi, F., Schepens, G.: Life below zero: bank lending under negative policy rates. Available at SSRN: https://ssrn.com/abstract=2788204 (2017) 
Kerbl, S., Sigmund, M.: From low to negative rates: an asymmetric dilemma. In OENB (ed.), Financial Stability Report, vol. 32, pp. 120-135 (2016)

Kerbl, S., Simunovic, B., Wolf, A.: Quantifying interest rate risk and the effect of model assumptions behind sight deposits. In OENB (ed.), Financial Stability Report, vol. 37, pp. 73-85 (2019)

Klein, M.: Implications of negative interest rates for the net interest margin and lending of euro area banks. Deutsche Bundesbank Discussion Paper No. 10/2020 (2020)

Lopez, J.A., Rose, A.K., Spiegel, M.M.: Why have negative nominal interest rates had such a small effect on bank performance? cross country evidence. Eur. Econ. Rev. 124, 103402 (2020)

Maddaloni, A., Peydró, J.-L.: Bank risk-taking, securitization, supervision, and low interest rates: evidence from the Euro-area and the US lending standards. Rev. Financ. Stud. 24(6), 2121-2165 (2011)

Memmel, C.: Banks' interest rate risk: the net interest income perspective versus the market value perspective. Quant. Finance 14, 1059-1068 (2014)

Memmel, C.: Why do banks bear interest rate risk? Schmalenbach Bus. Rev. 70(3), 231-253 (2018)

Memmel, C.: What drives the short-term fluctuations of banks' exposure to interest rate risk? Rev. Financ. Econ. 38(4), 674-686 (2020)

Memmel, C., Seymen, A., Teichert, M.: Banks' interest rate risk and search for yield: a theoretical rationale and some empirical evidence. Ger. Econ. Rev. 19(3), 330-350 (2018)

Molyneux, P., Reghezza, A., Thornton, J., Xie, R.: Did negative interest rates improve bank lending? J. Financ. Serv. Res. 57(1), 51-68 (2020)

Rajan, R.G.: Has financial development made the world riskier? NBER Working Paper No. 11728 (2005)

Wong, K.P.: On the determinants of bank interest margins under credit and interest rate risk. J. Bank. Finance 21, 251-271 (1997)

Publisher's Note Springer Nature remains neutral with regard to jurisdictional claims in published maps and institutional affiliations.

Ramona Busch is a senior economist at the Deutsche Bundesbank. Her field of work is stress testing, banks' interest income, and financial stability. She received her doctoral degree in economics from the University of Erlangen-Nürnberg.

Helge C.N. Littke is a financial economist in the department of Banking and Financial Supervision at Deutsche Bundesbank. He holds a doctoral degree from the TU Dresden in economics and has published academic articles in the fields of empirical banking and international financial markets.

Christoph Memmel is a senior economist in the Financial Stability Department of Deutsche Bundesbank. He did his doctorate in finance at the University of Cologne. His research interests are in the field of banks' interest income and the stability of the financial system.

Simon Niederauer is an economist in the Banking and Financial Supervision Department of Deutsche Bundesbank. His field of work is stress testing and quantitative analyses. 